\title{
Atividade antibacteriana in vitro de extratos de Rhizophora mangle L.
}

\author{
FERREIRA, F.S. ${ }^{1}$; SANTOS, S.C. ${ }^{1 *}$; BARROS, T.F. ${ }^{1}$; ROSSI-ALVA, J.C. ${ }^{2}$; FERNANDEZ, L.G. ${ }^{3}$ \\ ${ }^{1}$ Programa de Pós-Graduação em Microbiologia, Faculdade de Farmácia, Universidade Federal da Bahia, Ondina, \\ 40170-290, Salvador-Brasil *sidneibio@yahoo.com.br² Laboratório de Estudos em Meio Ambiente, Superintendência \\ de Pesquisa e Pós-Graduação, Universidade Católica do Salvador, Pituaçu, 41740-090, Salvador-Brasil ${ }^{3}$ Laboratório \\ de Bioquímica, Biotecnologia e Bioenergia, Departamento de Biofunção, Instituto de ciências da Saúde, Universidade \\ Federal da Bahia, Vale do Canela, 40160-000, Salvador-Brasil
}

\begin{abstract}
RESUMO: Ensaios para avaliar o potencial antibacteriano de Rhizophora mangle (mangue-vermelho), coletada no município de Conde, Bahia, foram realizados com cepas bacterianas Gram-positivas (Staphylococcus aureus ATCC 6538 e Micrococcus luteus ATCC 9341) e Gram-negativas (Echerichia coli ATCC 10536, Salmonella Cholerea-suis 10708, Klebsiela pneumoniae ATCC 700603 e Pseudomonas aeruginosaATCC 15442). A atividade antibacteriana foi avaliada pelos métodos de difusão em disco e concentração inibitória mínima (CIM), e os resultados analisados estatisticamente. Os resultados do ensaio de difusão em disco mostraram diferença significativa quanto à sensibilidade dos micro-organismos frente aos extratos testados $(p<0,05)$. A CIM do extrato da folha ( $\left.313 \mu \mathrm{g} \mathrm{mL}^{-1}\right)$ apresentou o melhor desempenho para inibir o crescimento das cepas Gram-positivas, enquanto o extrato da casca foi mais eficaz para as cepas Gram-negativas. De acordo com os dados levantados por este estudo, $R$. mangle apresentou propriedade antibacteriana para cepas Gram-positivas e Gram-negativas, podendo tornar-se alternativa terapêutica tanto para o uso popular quanto para a indústria farmacêutica.
\end{abstract}

Palavras-chave: Rhizophora mangle, extrato bruto, atividade antimicrobiana

ABSTRACT: In vitro antibacterial activity of Rhizophora mangle L. extracts. Assays to evaluate the antibacterial potential of Rhizophora mangle (red mangrove), sampled at Conde Municipality, Bahia State, Brazil, were performed against Gram-positive (Staphylococcus aureus ATCC 6538 and Micrococcus luteus ATCC 9341) and Gram-negative (Echerichia coliATCC 10536, Salmonella Cholerea-suis 10708, Klebsiela pneumoniae ATCC 700603 and Pseudomonas aeruginosaATCC 15442) bacteria. Antibacterial activity was evaluated by disc diffusion and minimal inhibitory concentration (MIC) and results were statistically analyzed. The results of disc diffusion assay showed a significant difference as to the sensitivity of microorganisms against the tested extracts $(p<0.05)$. The MIC of leaf extract $\left(313 \mu \mathrm{g} \mathrm{mL}^{-1}\right)$ indicated the best performance to inhibit the growth of Gram-positive strains, while bark extract had a better efficacy against Gram-negative strains. Based on the presented data, $R$. mangle showed antibacterial properties against both Gram-positive and Gram-negative strains and can be used as an alternative therapy for popular use or for the pharmaceutical industry.

Key words: Rhizophora mangle, crude extract, antimicrobial activity

\section{INTRODUÇÃO}

Durante a evolução os vegetais foram capazes de desenvolver diversos mecanismos para a sobrevivência e perpetuação. Alguns destes mecanismos estão envolvidos com a capacidade destes vegetais em resistir a ataques de microorganismos que, potencialmente, prejudicariam, de alguma forma, o desenvolvimento. Barreiras físicas e químicas foram surgindo a fim de manter a higidez do organismo vegetal (Eloff et al., 2004). A partir do século XIX a humanidade se deparou perplexa diante do diverso e inesgotável arsenal terapêutica presente nas plantas medicinais, devido à descoberta de substâncias ativas, que em estado natural ou após sofrerem processos de transformação química,

Recebido para publicação em 17/09/2009

Aceito para publicação em 11/01/2011

Rev. Bras. Pl. Med., Botucatu, v.13, n.3, p.305-310, 2011. 
possuem atividade biológica, muitas vezes já confirmada pelo uso popular e comprovada cientificamente (Miguel et al., 2005).

As espécies vegetais para uso medicinal têm recebido atenção especial pelos diferentes significados que as plantas medicinais assumem nas sociedades como recurso biológico e cultural, destacando-se o potencial genético para o desenvolvimento de novas drogas, possível fonte de recursos financeiros, através de sua comercialização para o resgate e fortalecimento da identidade cultural e como acesso primário à saúde de muitas comunidades (Da Silva, 2006).

O conhecimento sobre o potencial terapêutico dos vegetais tem despertado o interesse cientifico, buscando nesse conhecimento, novos caminhos para o controle e tratamento de diversas doenças (Coutinho, 2004). Pesquisas de tal natureza no Brasil são de grande valia, pelo fato do país ser considerado um dos maiores reservatórios de biodiversidade do mundo e, além disso, a grande extensão territorial abriga diversos tipos de ecossistemas, cada um com as particularidades, 0 que torna verdadeira fonte quase que inesgotável de moléculas a serem descobertas.

Rhizophora mangle L., conhecida popularmente como mangue-vermelho, é espécie endêmica da vegetação de manguezal pertencente à família Rhizophoraceae; possui caráter arbóreo com folhas simples e adaptações fisiológicas notáveis frente aos substratos anaeróbicos típicos do manguezal, os rizóforos. Tais estruturas são adaptações caulinares ricas em lenticelas, que aumentam a aeração e atuam diretamente na fixação da espécie no substrato lodoso (Lamberti, 1966). O mangue-vermelho é rico em substâncias fenólicas, como taninos, que são largamente utilizadas na produção de corantes. Algumas propriedades farmacológicas de $R$. mangle têm sido determinadas, como as atividades antiinflamatória (Marrero et al., 2006), antioxidante (Berenguer et al., 2006), cicatrizante (Fernandez et al., 2002); contra úlcera (Perera et al., 2001; Berenguer et al., 2006) e hipoglicêmica (Alarcon-Aguilara et al., 1998).

A descoberta de novas drogas para serem empregadas no controle de micro-organismos é de suma importância para a saúde populacional e campo promissor para o desenvolvimento técnico científico, visando à descoberta de novas moléculas que apresentem atividades biológicas importantes, como é o caso dos antimicrobianos. Tal fato vai fornecer informações científicas para populações que utilizam vegetais de forma empírica, contribuindo para a melhoria da saúde das pessoas que tem a natureza como a grande farmácia, além de possibilitar a geração de novas patentes de invenção e/ou de processos. Neste sentido, o presente trabalho teve como objetivo avaliar a atividade antibacteriana in vitro de extratos brutos da raiz, casca e folhas de Rhizophora mangle L., oriundas da região de Siribinha, situada no Município do Conde, Bahia, Brasil.

\section{MATERIAL E MÉTODO}

\section{Material Vegetal}

As partes vegetais (casca, raiz e folha) de Rhizophora mangle foram coletadas no município de Conde, na região litoral norte do Estado da Bahia, Brasil, entre as coordenadas 11\%46'43" latitude Sul e 37ㅇ32'36" longitude Oeste (Magellan, GPS 315), de acordo com a metodologia descrita por Campos (1991). A identificação da espécie foi realizada pelo Instituto Brasileiro de Geografia e Estatística (IBGE) e a exsicata se encontra depositada no acervo do Herbário Radambrasil (HRB) sob o número de registro 51500.

\section{Extrato Bruto}

Os extratos brutos foram preparados através do método de maceração (48 h), utilizando-se a proporção de 1:3, sendo $1 \mathrm{~g}$ de cada estrutura vegetal triturada para $3 \mathrm{~mL}$ de etanol (Merck) a $70 \%(\mathrm{v} / \mathrm{v})$ (Matos, 1997). Os extratos foram filtrados em papel filtro qualitativos (Quanty, ref. no JP42) num sistema de vácuo (Marconi, MA 057/1) e concentrados através do evaporador rotatório (Heidolph, Laborata 4000) a $40^{\circ} \mathrm{C}$, sob pressão reduzida, e por liofilização (Labconco, Freezone 4.5) para eliminação total do solvente (Santos et al., 2010). Os extratos foram armazenados em frasco âmbar e conservados no dessecador até o preparo das soluções em diferentes concentrações.

\section{Micro-organismos}

Seis cepas bacterianas foram usadas nos ensaios de sensibilidade: Staphylococcus aureus ATTC 6835, Micrococcus luteus ATCC 9341, Escherichia coli ATCC 10536, Pseudomonas aeruginosa ATCC 15442, Salmonella Cholerea-suis ATCC 10708 e Klebsiella pneumoniae ATCC 700603. As cepas bacterianas têm origem da bacterioteca do Instituto Nacional de Controle de Qualidade em Saúde (INCQS). As cepas bacterianas foram mantidas em agar triptcaseína de soja (TSA) (Merck) a $\pm 4^{\circ} \mathrm{C}$.

\section{Método de Difusão em Disco}

O ensaio antimicrobiano foi realizado através do método de difusão em disco (Bauer et al., 1966), com base no documento M2-A8 (NCCLS, 2003a), onde cada disco estéril de papel filtro (Qualit, ref. no 045.PF) de $6,0 \mathrm{~mm}$ de diâmetro foi impregnado com alíquotas $(10 \mu \mathrm{L})$ dos extratos de $R$. mangle nas concentrações de 1, 2 e $3 \mathrm{mg} \mathrm{disco}^{-1}$ (Santos et al.,

Rev. Bras. Pl. Med., Botucatu, v.13, n.3, p.305-310, 2011. 
2007). No teste controle negativo foi aplicado $10 \mu \mathrm{L}$ de dimetilsufóxido (DMSO) (Merck), utilizado na ressuspensão dos extratos, e como controle positivo foi usado os antibióticos eritromicina ( $15 \mu \mathrm{g}$ disco $\left.^{-1}\right)$ e ciprofloxacin $\left(5 \mu \mathrm{g} \mathrm{disco-}^{-1}\right)$ (Sensibiodisc, Cecon). O inóculo bacteriano foi preparado por suspensão direta em solução salina $(0,9 \%)$, a partir de cultura de $24 \mathrm{~h}$ em TSA. A suspensão foi ajustada através da escala padrão 0,5 de McFarland $\left(1,5 \times 10^{8} \mathrm{UFC} \mathrm{mL}^{-1}\right)$, sendo semeada em placa de Petri $(90 \mathrm{~mm}$ de diâmetro) contendo agar Mueller-Hinton (MHA, Himedia). Um conjunto predeterminado de discos de extratos vegetais foi colocado na superfície do $\mathrm{AMH}$. As placas foram incubadas na estufa a $37^{\circ} \mathrm{C}$ por 24 h. Após o período de incubação foi realizada a leitura do diâmetro dos halos de inibição total de crescimento bacteriano, incluindo o diâmetro do disco. Os halos foram medidos em milímetro com auxílio de halómetro.

\section{Determinação da concentração inibitória mínima (CIM)}

Os ensaios de sensibilidade de microdiluição em caldo foram feitos, seguindo as recomendações da National Committee for Clinical Laboratory Standards (2003b). Os testes foram realizados em caldo Mueller-Hinton ( $\mathrm{CMH}$, Himedia) contido em microplacas de 96 poços. Os extratos brutos da casca, raiz e folha de $R$. mangle foram aplicados nos poços, seguindo a técnica de diluição seriada, nas concentrações de $0.156,0.312,0.625,1.25,2.5,5$, $10,20 \mathrm{mg} \mathrm{mL}^{-1}$. Foi realizada diluição $(0.5,1,2,4,8$, $16,32 \mathrm{mg} \mathrm{mL}^{-1}$ ) de cloranfenicol (Henrifarma) como controle positivo e DMSO como controle negativo. A partir de uma suspensão ajustada da escala padrão 0,5 de McFarland das cepas bacterianas testadas, foram feitas diluições com água destilada de 1:10 (v/ v) para obter uma concentração final de bactérias de

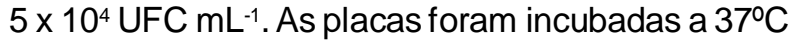
por $24 \mathrm{~h}$. A leitura foi realizada através da mudança de cor do revelador cloreto de 2,3,5 trifeniltetrazólio (TTC, Nuclear), considerando o resultado positivo a ausência de coloração e negativo na presença de coloração rosa-avermelhada (Santos et al., 2010).

\section{Análise Estatística}

Todos os testes de sensibilidade dos extratos vegetais foram realizados através de testes de KruskalWallis e Mann-Whitney, visando comparar as tendências centrais de inibição do crescimento bacteriano entre as estruturas vegetais (raiz, casca e folha) da espécie em estudo (Callegari-Jacques, 2003). Foi utilizado o programa estatístico GraphPad InsTat (versão 3) para análise dos dados. Os testes foram considerados significantes quando $o$ valor de $p$ foi menor que 0,05 .

\section{RESULTADO E DISCUSSÃO}

Os extratos vegetais apresentaram atividade antibacteriana frente aos micro-organismos testados, com exceção da E. coli. O extrato da casca foi capaz de inibir o crescimento das cepas ATCC nas três concentrações utilizadas (Tabela 1). O extrato da folha inibiu o crescimento das cepas Gram-positivas e de K. pneumoniae, sendo que para o M. luteus a inibição só foi evidenciada a partir da concentração de $2 \mathrm{mg}$ disco $^{-1}$. O extrato da raiz inibiu o crescimento das cepas de $K$. pneumoniae e $S$. Cholerea-suis nas três concentrações analisadas e o crescimento da cepa de $M$. luteus somente a partir de $3 \mathrm{mg} \mathrm{disco-1}^{-1}$. Os controles utilizados para a avaliação do desempenho dos ensaios corresponderam satisfatoriamente. $\mathrm{O}$ DMSO utilizado como controle negativo não inibiu o crescimento das cepas padrão e os antibióticos (Ciprofloxacin e Eritromicina) apresentaram halos de inibição de acordo ao perfil de sensibilidade descrito no NCCLS (2003a) (Tabela 1). A análise estatística mostrou que existe diferença significativa (KruskalWallis, $p<0,05$ ) entre os diâmetros dos halos de inibição dos micro-organismos para um mesmo extrato, sendo os valores de p: 0,01, 0,01 e 0,02 para as concentrações de $1,2 \mathrm{e} 3 \mathrm{mg} \mathrm{disco}^{-1}$, respectivamente. Para o extrato da raiz foram comparados somente os grupos bacterianos que apresentaram halos de inibição na concentração de $3 \mathrm{mg}$ disco-1.

Os extratos de $R$. mangle foram capazes de inibir o crescimento microbiano de duas das três espécies pertencentes a família Enterobacteriaceae. Entretanto, a diferença de atividade contra as enterobactérias parece derivar dos constituintes do extrato vegetal, principalmente do grupo dos taninos (Cimanga et al., 2002). A afinidade dos polifenóis por proteínas desempenha um importante papel na inativação de enzimas, impedindo o crescimento de alguns micro-organismos. Os polifenóis têm a propriedade de formar complexos com íons metálicos como ferro, vanádio, magnésio, alumínio e cálcio, resultando numa menor disponibilidade de íons para o metabolismo microbiano (Haslam,1996).

Foi observado aumento da resposta inibitória com o aumento das concentrações, com a exceção da cepa de K. pneumoniae que apresentou maior halo de inibição com o extrato da casca na concentração de $2 \mathrm{mg} \mathrm{mL}^{-1}$. Outro ponto a ser notado ocorreu com a cepa de $P$. aeruginosa, que apesar do aumento da concentração do extrato da casca não houve alteração nos valores dos halos de inibição, fato que pode estar relacionado ao processo de sinergismo, onde o componente com propriedade antimicrobiana pode ter se agregado a um elemento químico do extrato, beneficiando metabolicamente o crescimento bacteriano ou inibindo a ação antimicrobiana da molécula. 
TABELA 1. Média e desvio padrão dos halos de inibição $(\mathrm{mm})$ obtidos pelo método de difusão em disco com os extratos brutos (casca, folha e raiz) de $R$. mangle frente às cepas padrão.

\begin{tabular}{c|c|c|c|c|c|c|c|c|c}
\hline \multirow{2}{*}{ Micro-organismo } & $\begin{array}{c}\text { Concentração } \\
\mathrm{mg} \mathrm{disco}^{-1}\end{array}$ & \multicolumn{2}{|c|}{ Casca } & \multicolumn{2}{c|}{ Folha } & \multicolumn{2}{c|}{ Raiz } & ERI & CIP \\
& 1 & 8,0 & $\pm 0,0$ & 7,0 & $\pm 0,0$ & - & & 26,0 & \\
& 2 & 10,0 & $\pm 0,0$ & 8,0 & $\pm 0,0$ & - & & 26,0 & \\
S. aureus & 3 & 13,3 & $\pm 1,0$ & 10,0 & $\pm 0,0$ & - & & 26,0 & \\
\hline \multirow{3}{*}{ M. luteus } & 1 & 10,0 & $\pm 0,0$ & & & - & & 16,0 & \\
& 2 & 12,0 & $\pm 0,0$ & 10,0 & $\pm 0,0$ & - & & 16,0 & \\
& 3 & 14,3 & $\pm 1,0$ & 12,0 & $\pm 0,0$ & 9,3 & $\pm 0,9$ & 18,0 & \\
\hline \multirow{3}{*}{ E.coli } & 1 & - & & - & & - & & 12,0 & \\
& 2 & - & & - & & - & & 12,0 & \\
\hline \multirow{3}{*}{ K.penumoniae } & 3 & - & & - & & - & & 14,0 & \\
\hline \multirow{3}{*}{ P.aeruginosa } & 1 & 12,0 & $\pm 0,0$ & 10,0 & $\pm 0,0$ & 7,0 & $\pm 0,0$ & & 26,0 \\
& 2 & 14,0 & $\pm 0,0$ & 12,0 & $\pm 0,0$ & 9,3 & $\pm 0,5$ & & 26,0 \\
& 3 & 11,3 & $\pm 1,0$ & 12,0 & $\pm 0,5$ & 12,7 & $\pm 0,9$ & & 28,0 \\
\hline \multirow{3}{*}{ S. Cholerea-suis } & 2 & 8,0 & $\pm 0,0$ & - & & - & & & 36,0 \\
& 3 & 8,0 & $\pm 0,0$ & - & & - & & & 36,0 \\
& 1 & 7,7 & $\pm 1,0$ & - & & - & & & 38,0 \\
\hline
\end{tabular}

* Halos de inibição incluindo o diâmetro do disco $(6 \mathrm{~mm})$; "Ausência de inibição; MA média aritmética do diâmetro do halo de inibição bacteriana; $D P$ desvio padrão do diâmetro do halo de inibição bacteriana; ERI eritromicina (15 $\mu \mathrm{g}$ disco-1); CIP ciprofloxacin $(5 \mu \mathrm{g}$ disco-1).

A concentração inibitória mínima do extrato da folha apresentou o melhor desempenho para inibir o crescimento das cepas Gram-positivas, enquanto o extrato da casca foi mais eficaz para as cepas Gram-negativas (Tabela 2). A utilização de formulações de $R$. mangle contra processos infecciosos provocados por Salmonela precisam ser melhor estudadas, mas o fato de ter sido encontrada uma boa sensibilidade da bactéria do mesmo gênero utilizada neste trabalho, permite inferir que os extratos são promissores para serem utilizados contra infecções causadas por causada pela bactéria Salmonella. O extrato da raiz apresentou à maior $\mathrm{CIM}$ (1250-2500 $\mathrm{g} \mathrm{m} \mathrm{mL}^{-1}$ ) quando comparado com as outras partes vegetais, indicando que as moléculas bioativas com propriedades antimicrobianas estão distribuídas em maiores concentração na casca e na folha. Os extratos da casca, folha e raiz mostraram diferença significativa $(p=0.0183)$ quando comparados entre si, pelo método de Kruskal-Wallis. Os resultados encontrados para os valores da CIM do Cloranfenicol (Tabela 2) estão de acordo com as normas da Clinical and Laboratory Standards Institute (2005).

O potencial antibacteriano dos extratos brutos de $R$. mangle confirma os relatos da literatura com outro membro da família Rhizophoraceae, Rhizophora apiculata, que possui o constituinte 2,6dimethoxy-p-benzoquinone com atividade inibitória contra fungos e bactérias (Kokpol et al., 1993). Estudo com o extrato da casca de $R$. apiculata revelou que tanino hidrossolúvel possui atividade antimicrobiana (Lim et al., 2006). A ação anti-séptica e antimicrobiana de $R$. mangle parece estar ligada em grande parte a presença dos taninos. Segundo Sánchez et al. (1998), o extrato aquoso da casca de $R$. mangle apresenta polifenóis $(80 \%)$, representados na maioria por taninos poliméricos ( $80 \%$ ) e taninos hidrolisáveis $(20 \%)$, onde se destacam as presenças de epicatequina, catequina, ácido clorogênico, ácido gálico, ácido elágico, assim como galotaninos, elagitaninos e taninos condensados. Outras estruturas são relatadas, entre elas carboidratos livres e polomerixados (xilose, ramnose, fucose, glicose, arabinose, manose e galactose), ácidos graxos de cadeias longas saturadas e insaturadas (C12:0 até C24:0), óleos essenciais e fitoesteróies. Todos estes grupos mostraram atividade antimicrobiana contra cepas de Bacillus subtilis e Staphylococcus aureus. 
TABELA2. Determinação da concentração inibitória mínima dos extratos de $R$. manglefrente a cepas bacterianas ATCC.

\begin{tabular}{l|c|c|c}
\hline \multirow{2}{*}{ Micro-organismo } & \multirow{2}{*}{ Parte Vegetal } & \multicolumn{2}{|c}{ CIM $\left(\mu \mathrm{g} \mathrm{mL}^{-1}\right)$} \\
& & Extrato & Cloranfenicol \\
\hline S. Cholerea-suis & & 625 & 8 \\
S. aureus & \multirow{2}{*}{ Casca } & 625 & 16 \\
K. peneumoniae & & 313 & 4 \\
M. luteus & & 156 & 8 \\
\hline S. aureus & & 313 & 16 \\
K. peneumoniae & Folha & 1250 & 8 \\
M. luteus & & 313 & 4 \\
\hline S. Cholerea-suis & & 2500 & 8 \\
K. pneumonia & Raiz & 1250 & 4 \\
M. luteus & & 2500 & 8 \\
\hline
\end{tabular}

Rhizophora mangle é vegetal bastante estudado na América Central. Cuba apresenta um dos maiores, se não o maior número de publicações referentes ao uso terapêutico da espécie tanto na medicina humana quanto na veterinária. Fernandez et al. (2002) avaliaram o poder cicatrizante e antiséptico do mercúrio-cromo e do extrato da $R$. mangle em feridas cirúrgicas, obtendo melhor resultado nos pacientes que foram tratados com o extrato. Relata também que a película formada pela interação do extrato com as proteínas favorece o isolamento do tecido do meio externo, acelerando o processo de cicatrização e prevenindo infecções secundárias. $O$ gênero Rhizophora possui determinadas substâncias presentes no extrato, como por exemplo, os taninos e polifenóis (Bandaranayake, 2002), que são capazes de interagir com estruturas peptídicas formando grandes aglomerados, o que mais uma vez explicaria a formação da película protetora.

No Brasil, o aumento acentuado do consumo de fitoterápicos ocorre basicamente pelos mesmos motivos do restante do mundo. Contudo, existe atualmente maior número de profissionais envolvidos nos mais diversos trabalhos com plantas medicinais e/ou fitoterápicos, seja na pesquisa, fomento ou difusão. Outro motivo de suma importância são os programas oficiais de saúde implementados por muitos governos estaduais e municipais, como as ações desenvolvidas nos Estados do Ceará e Paraná. Esses programas vãos além da simples distribuição de fitoterápicos ou recomendação de uso para a população mais carente desses estados/municípios. Procuram também incentivar o cultivo e produção extrativa sustentável de plantas medicinais. Dessa maneira, também são criadas alternativas econômicas para as comunidades rurais, que a cada dia perdem o poder de competitividade diante da chamada "economia globalizada" (Souza \& Miranda, 2006). Porém, é fundamental a realizações dos testes toxicológicos e imunológicos antes da possível utilização de plantas medicinais com fins terapêuticos.

Este estudo demonstrou o potencial antibacteriano dos extratos brutos da casca, folha e raiz de $R$. mangle, confirmando os relatos da família Rhizophoraceae como interessante fonte de constituintes antibacterianos. As análises mostraram que não existe uma parte botânica com maior atividade, pois todas apresentaram perfis antibacterianos diferenciados. Este estudo serve de subsídio a futuros experimentos que visem elucidar as substâncias ativas dos extratos de R. manglecom atividade antimicrobiana, além de ratificar a importância das informações etnofarmacológicas de muitas comunidades tradicionais para seleção de plantas com propriedades biológicas.

\section{AGRADECIMENTO}

Ao Laboratório de Estudos em Meio Ambiente (LEMA) da Universidade Católica do Salvador (UCSal) e ao Laboratório de Pesquisa em Microbiologia Clínica (LPMC) da Universidade Federal da Bahia (UFBA).

\section{REFERÊNCIA}

ALARCON-AGUILARA, F.J. Study of the anti-hyperglycemic effect of plants used as antidiabetics. Journal of Ethnopharmacology, v.61, n.2, p.101-9, 1998.

BANDARANAYAKE, W.M. Bioactivities, bioactive compounds and chemical constituents of mangrove plants. Wetlands Ecology and Management, v.10, p.42152, 2002.

BAUER, A.W. et al. Antibiotic susceptibility testing by 
standardized single disk method. American Journal of Clinical Pathology, v.45, p.493-6, 1966.

BERENGUER, B. et al. Protective and antioxidant effects of Rhizophora mangle L. against NSAID-induced gastric ulcers. Journal of Ethnopharmacology, v.103, n.2, p.194200, 2006.

CAMPOS, J.M. Guia prático de terapêutica externa: métodos e procedimentos terapêuticos de grande simplicidade e eficácia. São Paulo: Cultrix/Pensamento, 1991. 219p.

CALLEGARI-JACQUES, S.M. Bioestatística: princípios e aplicações. Porto Alegre: Artmed, 2003. 184p.

CIMANGA, K. et al. Correlation between chemical composition and antibacterial activity of essential oils of some aromatic medicinal plants growing in the Democratic Republic of Congo. Journal of Ethnopharmacology, v.79, n.2, p.213-20, 2002.

CLINICAL AND LABORATORY STANDARDS INSTITUTE CLSI. Performance standards for antimicrobial susceptibility testing; fifteenth informational supplement. Pennsylvania: CLSI/NCCLS, 2005. (document M100-S15). COUTINHO, H.D.M. et al. Atividade antimicrobiana de produtos naturais. Revista Conceitos, v.77, p.77-85, 2004. DASILVA, M.S. Uso e avaliação farmacológica de plantas medicinais utilizadas na medicina popular do povoado Colônia Treze em Lagarto/SE. Disponível em: <http:// www.herbario.com.br/atual03/2311 plantmed.htm>. Acesso em: 26 ago. 2006.

ELOFF, J.N.; MARTINI, N.D.; KATERERE D.R.P. Biological activity of five antibacterial flavonoids from Combretum erytrophyllum (Combretaceae). Journal of Enthnopharmacology, v. 93, p.207-12, 2004.

FERNANDEZ, O. et al. Efficacy of Rhizophora mangle aqueous bark extract in the healing of open surgical wounds. Fitoterapia, v.73, n.7-8, p.564-8, 2002.

HASLAM, E. Natural polyphenols (vegetable tannins) as drugs: possible modes of action. Journal of Natural Products, v.59, p.205-15, 1996.

KOKPOL, U. et al. Long-chain aliphatic-alcohols and saturated carboxylic-acids from heartwood of Rhizophora apiculata. Phytochemistry, v.33, p.1129-31, 1993.

LAMBERTI,A. Contribuição ao conhecimento da ecologia das plantas de manguezal de Itanhém. 1966. 217p. Tese
(Doutorado em Ciências) - Instituto de Biociências, Universidade de São Paulo, São Paulo.

LIM, S.H. et al. Antimicrobial activities of tannins extracted from Rhizophora apiculata barks. Journal of Tropical Forest Science, v.18, p.59-65, 2006.

MARRERO, E. et al. COX-2 and SPLA2 inhibitory activity of aqueous extract and polyphenols of Rhizophora mangle (red mangrove). Fitoterapia, v.77, n. 4, p.313-5, 2006.

MATOS, F.J.A. O formulário fitoterápico do professor Dias

da Rocha: informações sobre o emprego na medicina caseira, de plantas do Nordeste, especialmente do Ceará. 2.ed. Fortaleza: UFC, 1997. 260p.

MIGUEL, O.G. et al. Estudo preliminar da atividade antimicrobiana das cascas de Erythrina velutina Willd Fabaceae (Leguminosae). Brasilian Journal of Pharmacognosy, v.15, n.2, p.137-42, 2005.

NATIONAL COMMITTEE FOR CLINICAL LABORATORY STANDARDS - NCCLS. Performance standards for antimicrobial disk susceptibility tests: approved standard. 8.ed. Pennsylvania: NCCLS, 2003a. (document M2-A8). NATIONAL COMMITTEE FOR CLINICAL LABORATORY STANDARDS - NCCLS. Methods for dilution antimicrobial susceptibility tests for bacteria that grow aerobically: approved standard. 6.ed. Pennsylvania: NCCLS, 2003b. (document M7-A6).

PERERA, L.M.S.; RUEDAS, D.; GÓMEZ, B.C. Gastric antiulcer effect of Rhizophora mangle L. Journal of Ethnopharmacology, v.77, n.1, p.1-3, 2001.

SÁNCHEZ, L.M. et al. Caracterización química y toxicológica de una formulación acuosa de Rhizophora mangle L. Revista de Salud Animal, v.20, p.69-72, 1998. SANTOS, S.C. et al. Atividade antimicrobiana in vitro do extrato de Abarema cochliocarpos (Gomes) Barneby \& Grimes. Revista Brasileira de Farmacognosia, v.17, n.2, 215-9, 2007.

SANTOS, S.C. et al. Avaliação da atividade antibacteriana dos extratos de Avicennia schaueriana Stapf \& Leechm. ex Moldenke, Verbenaceae. Revista Brasileira de Farmacognosia, v.20, n.1, 124-9, 2010.

SOUZA, J.A.; MIRANDA, E.M.M. Plantas medicinais e fitoterápicos: alternativas viáveis. Embrapa Acre. Disponível em: <http://www.cpafac.embrapa.br/chefias/ cna/artigos/ planmed.htm>. Acessado em: 15 ago. 2006. 